\title{
Structure and Properties of the Billet of PT-1M Alloy after Expanding
}

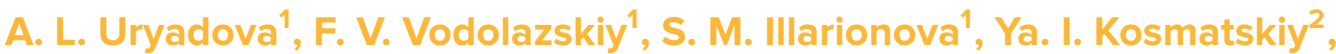 \\ E. A. Gornostaeva ${ }^{2}$, N. A. Barannikova1, and A. G. Illarionov ${ }^{1}$ \\ ${ }^{1}$ Ural Federal University, 19, Mira str., Ekaterinburg, Russian Federation \\ 2 JSC RosNITI, 30, Novorossiiskay street, Chelyabinsk, Russia
}

\section{Abstract}

In this paper the macro-, microstructure, the hardness and the modulus of elasticity for the billet of the PT-1M alloy after expanding was studied. It was shown the expanding resulted to grain refinement near inner surface of the billet due to the recrystallization. The relationship between the structure through sections, the hardness and the modulus of elasticity was established.

Keywords: titanium alloy PT-1M, expanding, macrostructure, microstructure, hardness,

Corresponding Author:

F. V. Vodolazskiy

f.v.vodolazskiy@urfu.ru

Received: 25 February 2019

Accepted: 9 April 2019

Published: 15 April 2019

Publishing services provided by

Knowledge E

(c) A. L. Uryadova et al. This article is distributed under the terms of the Creative Commons Attribution License, which permits unrestricted use and redistribution provided that the original author and source are credited.

Selection and Peer-review under the responsibility of The Ural school-seminar of metal scientists-young researchers Conference Committee. modulus of elasticity.

\section{Introduction}

Expanding is the operation of dilatation of central hole in a pre-drilled tubular billet using a special-shaped needle tip on piercing presses, which provides the size and shape formation of the tube billet to the required size for subsequent pressing [1]. Expanding does not require recompacting of the billets and allows to get billets of larger length than with piercing. The hot plastic deformation occurs during expanding, which can result to the structure and property changes along the cross section. The grain structure of hot worked tube billet can be not uniform through cross section, which leads to deviations of mechanical properties through section of the billet. In this paper, the influence of the expanding operation on the structure and properties of a tube billet of widely used PT-1M alloy [2] were studied.

\section{Research Material and Methods}

The material for the study was templates of alloy PT-1M (Ti-0.4AI-0.080, wt. \%) which cut from a tubular billet. The drilling and expanding at a temperature of $850{ }^{\circ} \mathrm{C}$ were performed at Volzhsky Pipe Plant. Diameter of needle tip was $\varnothing 86 \mathrm{~mm}$. The expanding 
temperature was selected according to the calculations of the energy-force parameters of the deformation via temperature of a hot-forged tubular billet of PT-1M alloy [3]. Typical dimensions of the shell-billet obtained during expanding: outer diameter $189 \mathrm{~mm}$, wall thickness $52 \mathrm{~mm}$.

The following types of analysis were used: macrostructural - using the scale method [5], microstructural - using an Olympus GX51 microscope, X-ray difraction analysis (XRDA) - using a Bruker D8 Advance diffractometer (Cu $\mathrm{K}_{\alpha}$-radiation), microindentation with determination Vickers microhardness and contact modulus of elasticity using the MHTX CSM Instruments instrument according to the method of Oliver and Pharr [5] with a load of $9 \mathrm{~N}$. The structure analysis was performed on the transverse and longitudinal sections of the templates after the etching in a $15 \%$ solution of hydrofluoric acid (for macrostructure) and after etching in aqueous solution of nitric and hydrofluoric acids in a ratio of 1 part $\mathrm{HF}+3$ parts $\mathrm{HNO} 3+5$ parts $\mathrm{H} 2 \mathrm{O}$ (for microstructure).

\section{Results and Discussion}

The macrostructure of the PT-1M titanium alloy after expanding is shown in Fig. 1 and generally consists of equiaxed grains. Near the inner and outer surfaces the macrograins are smaller and have 2-3 macrograin size number, and in the center of the templet the larger grains are about 6-7 macrograin size number according to the macrostructure grain size scale of titanium alloys [4]

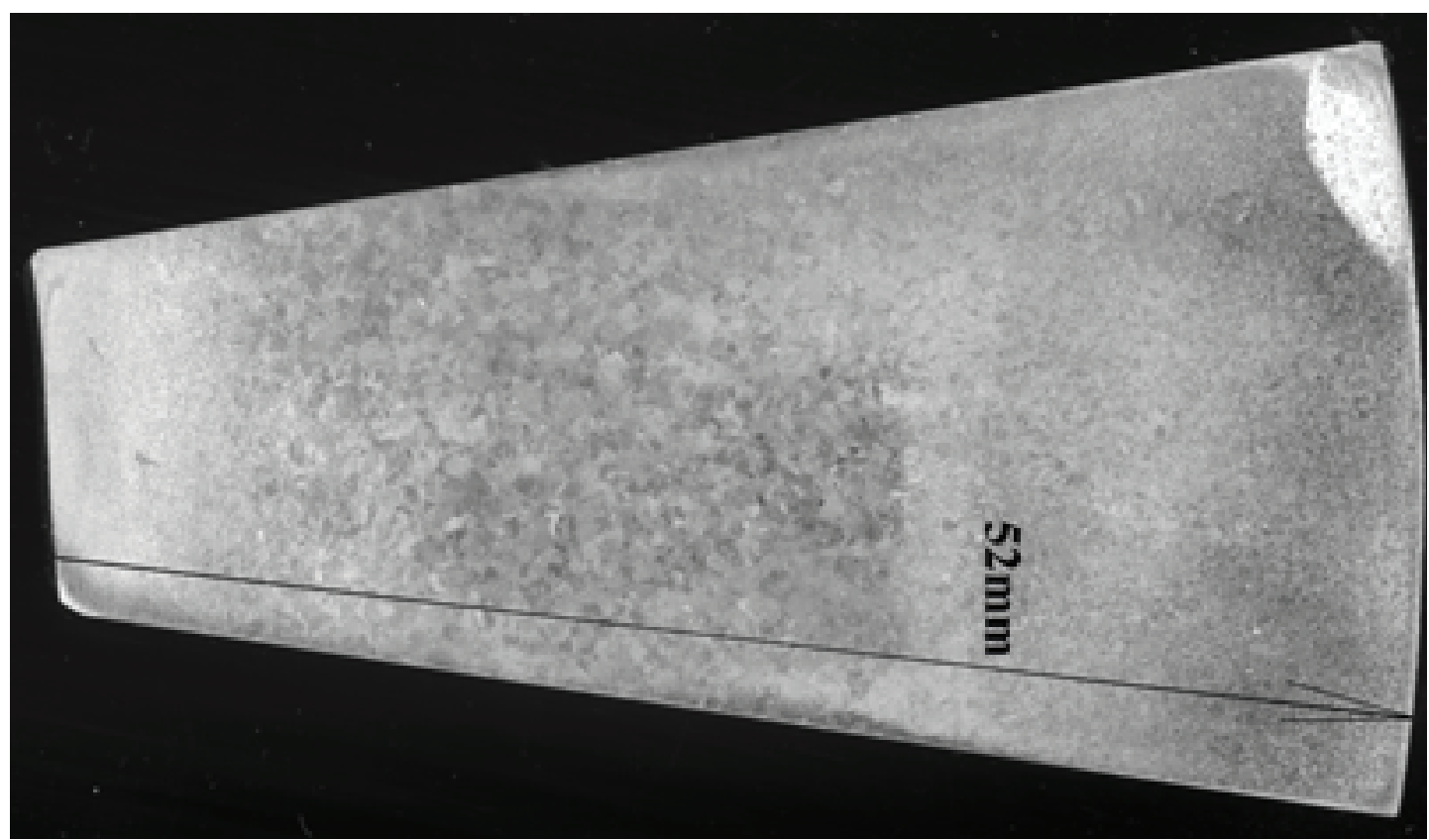

Figure 1: The macrostructure of the template after expanding in transverse section. 
Expanding rusulted to some refining of macrograin structure of central area of the shell-billet (macrograin size number decreased from 9-10th to 6-7th), significant refining of the macrograin at the inner surface (macrograin size number decreased from 9-10th to 2-3th) and practically did not affect the macrograin at the outside surface. The observed effect is associated with the development of primary recrystallization processes during expanding. The temperature of begging recrystallization process of technical titanium alloy VT1-0, which has slightly different chemical composition to PT-1M, is $700^{\circ} \mathrm{C}$ and the expanding temperature is $850^{\circ} \mathrm{C}$ which exceed the temperature of the end of recrystallization process of the VT1-O alloy. This means that recrystallization process took place during plastic deformation. The inner area of the shell-billet had the highest deformation degree and a minimum grain size was formed. The deformation degree in the central area lower thus recrystallization effect is lower too. The outer area are less deformed during expanding, moreover, ordinary the recrystallizing took place during hot forging of initial pipe billet. Therefore the macrograin size of this area practically did not change during expanding.

Analysis of microstructures in the longitudinal and transverse section of the expanded shell-billet showed that outer and center areas and have an equiaxial grain structure (Fig. 2). The microstructure was evaluated by 9 th grain size number of microstructures of $\alpha$ titanium alloys [7]. The outer area is characterized by recrystallized grains with a size is about $250 \mu \mathrm{m}$ ( $3 \mathrm{~d}$ grain size number), and annealing twins inside the grains are observed in both sections (Fig. 2 c, f). In the center of the liner there is a rough feathery structure, the size of individual grains is about $1 \mathrm{~mm}$ (6 grain score) (Fig. $2 b, e)$. In the inner area in the longitudinal direction there is a feathery structure too, but it elongated at an angle of $45^{\circ}$ (Fig. $2 a, d$ ). The thickness of the plates was more than 500 microns, and a length of more than $2 \mathrm{~mm}$ (5-6 grain size number) (Fig. 2 a, d). Individual recrystallized grains with annealing twins are observed.

The XRDA- patterns of sections cut from different areas in longitudinal and transverse sections of the shell-billet are shown in Fig. 3. All diffraction patterns taken from different sections had only $\alpha$-phase lines with periods $a=0.2951 \pm 0.0005 \mathrm{~nm}, c=0.4686 \pm$ $0.0002 \mathrm{~nm}$, and the parameter $c / a=1.5875$ slightly above the $\alpha$-phase parameter of pure titanium $(1,587)[8]$ due to the aluminum alloying.

The texture analysis shows the $(101)_{\alpha}$ has highest intensity both longitudinal and transverse sections except the outer area of transverse section. The intensification of prism plane $(100)_{\alpha}$ is observed in the outer and inner area of transverse section, which is not occurred in the central area. The pyramidal plane $(101)_{\alpha}$ is lower in inner area of 


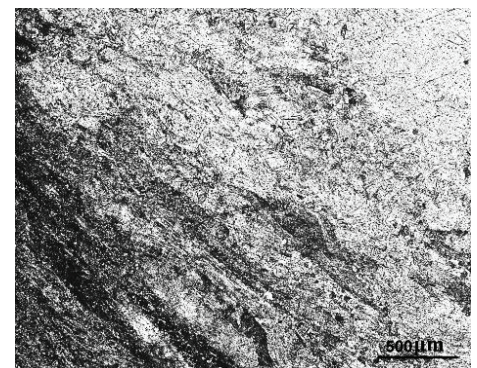

$a$

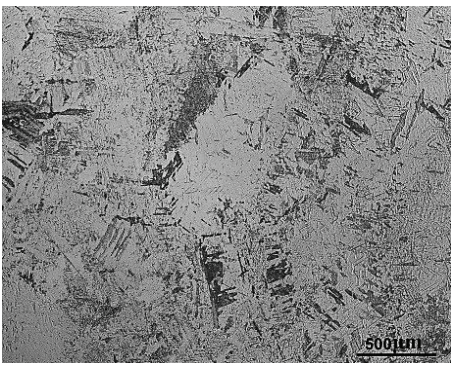

$d$

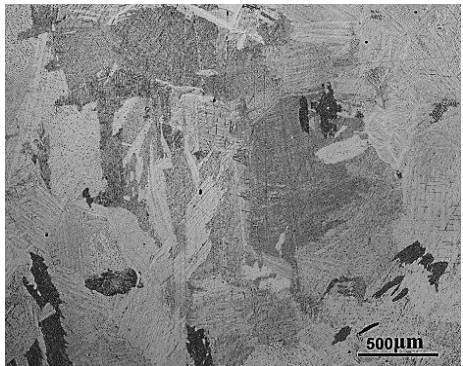

$b$

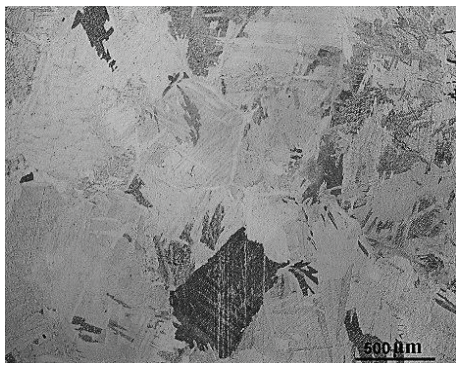

$e$

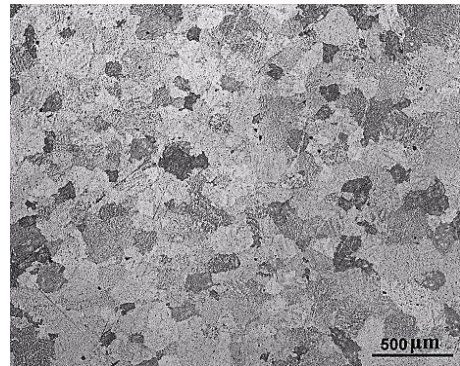

$c$

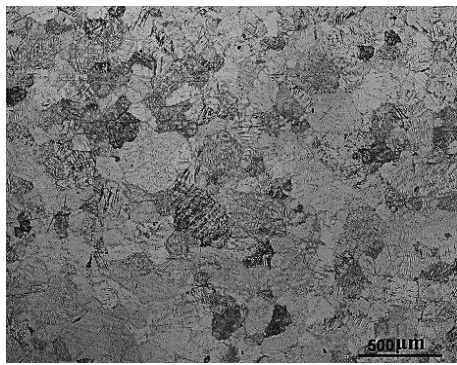

$f$

Figure 2: The microstructure of the shell-billet of the PT-1M alloy in longitudinal $(a, b, c)$ and transverse section $(d, e, f): a, g$, inner surface; $b, d$, - center; $c$, e - outer surface.

transverse section. Thus this shows the crystallographic texture formation in the shellbillet during expanding.

Microdurometry data and measurements of the modulus of elasticity from different sections after expanding are shown in Fig. 4.

Analysis of histograms showed that higher average values of microhardness 165-175 $\mathrm{HV}$ in both longitudinal and transverse direction exhibits areas near the outer and inner surface of the shell-billet. According to the structural analysis data these areas have a finer-grained structure compared to the central areas where the grain is larger (Fig. 1, 2) and a lower microhardness $153 \mathrm{HV}$ (Fig. 4a). It is well known that microhardness of a single-phase alloy have the inverse relation with the grain size according to the Hall Petch relationship [9].

The values of the contact modulus of elasticity are comparable within the section, the deviations are within the error limits. The averaged value of the elastic modulus in the longitudinal direction is higher ( $106 \pm 3 \mathrm{GPa}$ ) than in the transverse direction ( $96 \pm 3 \mathrm{GPa}$ ). Obviously, this difference is related to the crystallographic texture found in the shell-billet according to the XRDA analysis (Fig. 3). Thus higher values of the elastic modulus in the longitudinal section are determined by a large number of grains in this section with the orientations 101 and 002 , that is, along the "c"-direction of the HCP-lattice of $\alpha$-phase, which is characterized by the maximum value of the elastic modulus [10]. In the cross 


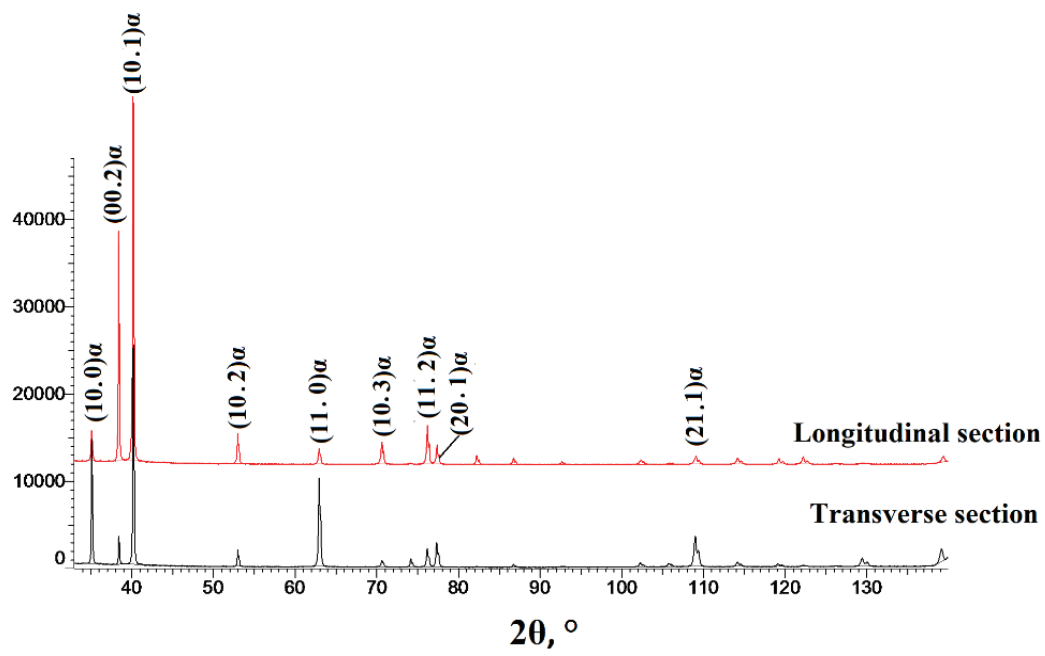

$a$

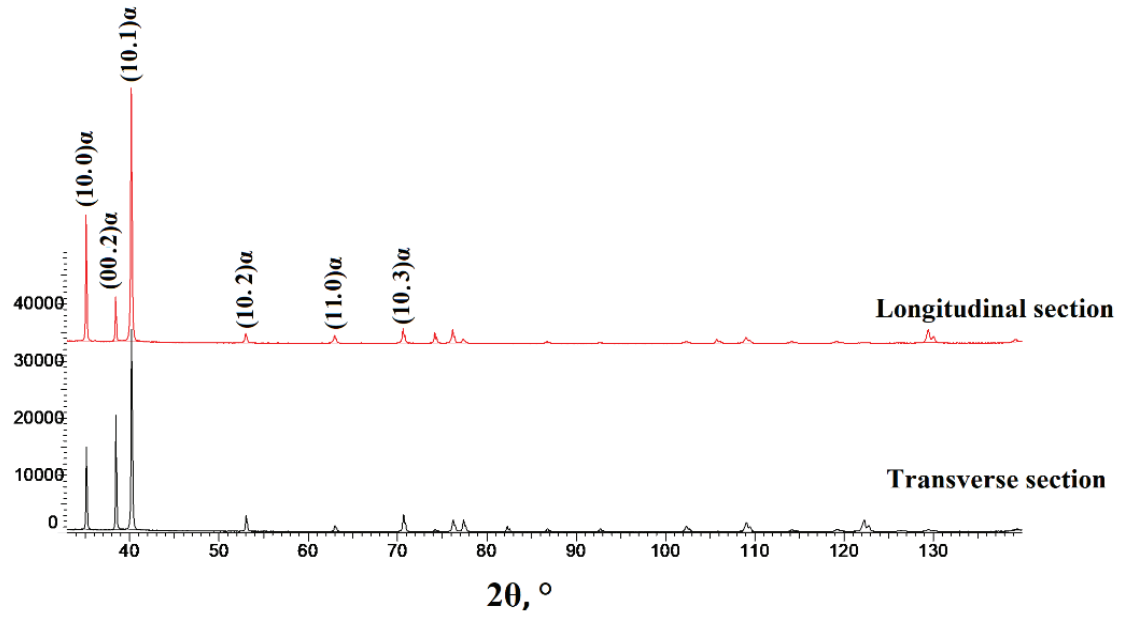

$b$

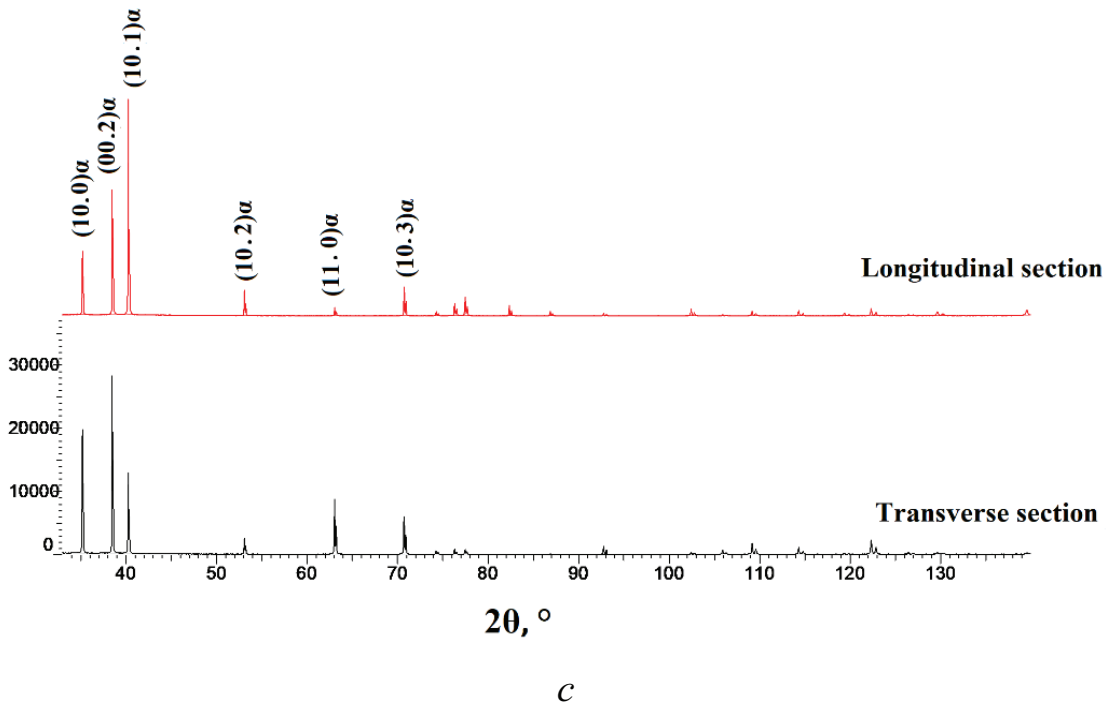

Figure 3: Diffraction patterns taken from samples cut out near the outside surface $(a)$, center $(b)$, inside surface $(c)$ of the shell-billet.

section, the high modulus orientations 101 and 002 are generally weaker (Fig. 3) and the 


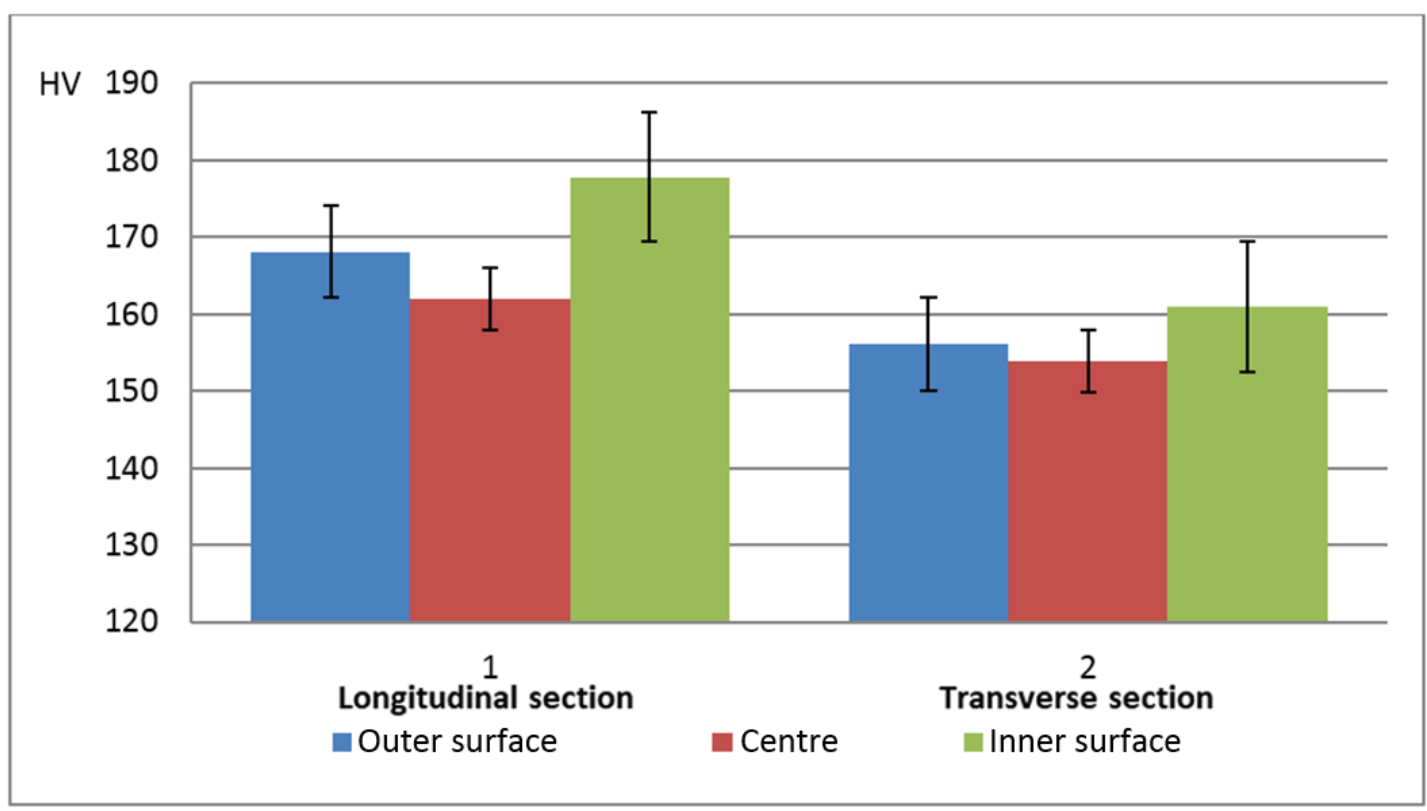

$a$

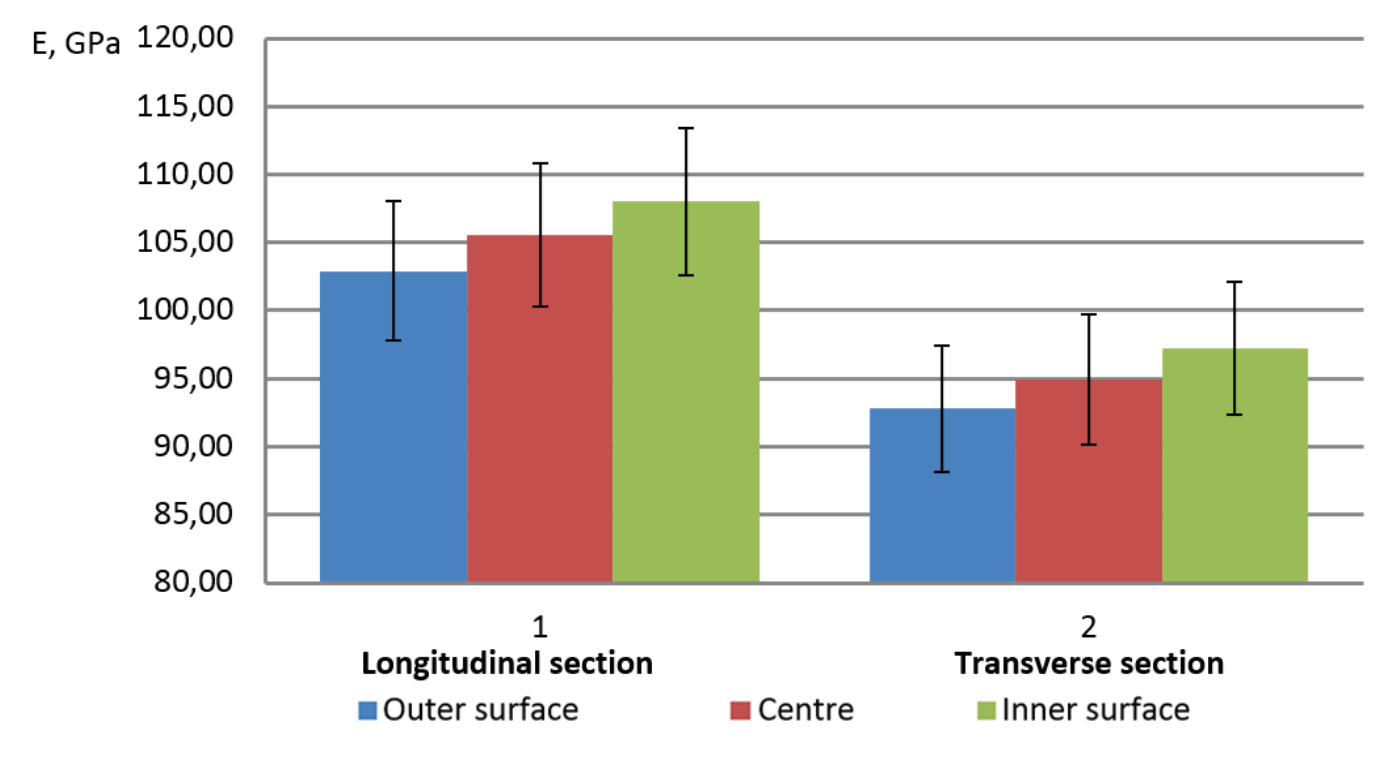

$b$

Figure 4: Histogram of average values of microhardness $(a)$ and modulus of elasticity $(b)$ in different sections and areas of the shell-billet after expanding.

intensity of the lower modulus orientations 100 is higher [10]. This result to a lower level of the elastic modulus than in the longitudinal section. The average modulus of elasticity of whole sections is $101 \pm 3 \mathrm{GPa}$ and is close to the $104 \mathrm{GPa}$ given in the literature [11]. It is characteristic for polycrystalline technical titanium, which is slightly different in chemical composition of the PT-1M alloy. 


\section{Conclusion}

The study of the shell-billet of the PT-1M alloy showed that the expanding at $850{ }^{\circ} \mathrm{C}$ resulted to grain refining in the central region and especially near the inner surface due to the development of recrystallization processes. The crystallographic texture across section is developed during expanding, which determines the difference of the level of the elasticity modulus in the longitudinal and transverse section. The hardness after expanding is higher in the outer and inner areas of the sections, which correlates with the grain size distribution.

The study was supported by Russian Science Foundation, grant 18-79-10107.

The work was carried out using the laboratory equipment "Structural methods of analysis and properties of materials and nanomaterials" of the Center of Ural Federal University.

\section{References}

[1] B.V. Barichko, Ya.I. Kosmatsky, K.Yu. Panov. Technology of pressing processes Chelyabinsk. SUSU Publishing Center, 2011. 70 p.

[2] A.A. Ilyin, B.A. Kolachev, I.S. Polkin. Titanium Alloys. Composition, Structure, Properties. Reference book. Moscow, VILS-MATI, 2009. 520 p.

[3] Kosmatskiy Ya.I., Fokin N.V., Filyaeva E.A., Barichko B.V. Study on the Deformation Ability Billets of Titanium Alloy Grade PT-1M. Bulletin of the South Ural State University. Ser. Metallurgy, 2017, V. 17, №. 4, pp. 83-91.

[4] S.G. Glazunov, B.A. Kolachev, Titanium alloys. Metallography of titanium alloys, M.: Metallurgy, 1980. 464 p.

[5] W.C. Oliver, G.M.Pharr An improved technique for determining hardness and elastic modulus using load and displacement sensing indentation experiments. // Journal Materials Research. 1992. V.7. №6. P.1564-1583.

[6] S.G. Glazunov, V.N. Moiseev, Structural titanium alloys. M.: Metallurgy. 1974. 368 p.

[7] L.A. Nikolsky, Hot stamping and pressing of titanium alloys, M.: Mashinostroenie, 1975, 285 p.

[8] Popov AA, Metallurgy and heat treatment of titanium alloys. Structure and properties / A.G. Illarionov, N.G. Rossina, S.V. Grib. Ekaterinburg: UrFU, 2012. 268 p. 
[9] Degtyarev, M.V., Chashchukhina, T.I., Voronova, L.M., Patselov, A.M., Pilyugin, V.P.Influence of the relaxation processes on the structure formation in pure metals and alloys under high-pressure torsion // Acta Materialia, 2007, 55 (18), P. 6039-6050.

[10] U. Zwicker Titan and its alloys, M.: Mir. 1979. 512 p.

[11] Kolachev B.A., Elagin V.I., Livanov V.A. Metal Science and Heat Treatment of NonFerrous Metals and Alloys. Moscow: MISIS Publ., 2001, 416 p. 